\title{
Service projects and women's agency in Salalah, Oman: A portrait of pre-service Dhofari English teachers
}

\author{
Robin Ann Martin* \\ Graduate School of Education, Main Campus, G-263 Bilkent University, 06800 Ankara, Turkey
}

\section{A R T I C L E I N F O}

\section{Keywords:}

Teacher education

Oman

Arab women

Agency

Curriculum policy

Service learning

\begin{abstract}
A B S T R A C T
This research examines the service learning activities and written discourse of pre-service teachers from a cohort of 50 young women who were among the first generation in their community to complete a local university education with BA degrees in English language and literature combined with a subsequent teaching diploma to become English teachers. Based on written reports about service projects completed at the end of teacher training, the dominant theme that emerges is that of women's agency. Discourse analysis is used to create a portrait of how Dhofari women are learning to take agency and gradually developing their own unique views within student-centered learning.
\end{abstract}

(c) 2011 Elsevier Ltd. All rights reserved.

\section{Situating the story in its social and cultural contexts}

\subsection{Introduction}

In spring of 2009, I was preparing to leave Salalah, a small southern city in the Dhofar region of The Sultanate of Oman. After three years as a teacher educator, I had learned much about the tribes, families, and individuals who call themselves Dhofaris. In particular, I had learned about young women enrolled in a private university on a career path to become English teachers. As the third group of women who stayed in their own local area to complete a four-year degree and go on to pursue a one-year teaching diploma, these young women were pushing their social and educational boundaries. After pursuing the requisite university education and training necessary to become teachers, what kinds of choices and actions were these women ready and willing to take? What qualities did they have that would allow them to take responsibility in bringing new student-centered ideas and educational practices into schools? Moreover, what are the implications for advancing the new student-centered approaches to learning that have been integrated into the national English curriculum?

The present research offers a view of rural Arab women that highlights their agency and determination in the face of unfolding opportunities that were not available to their mothers. Although these young women live in a socially conservative society that has traditionally partitioned the social role of women to the private domain, a closer look reveals women who are taking new

\footnotetext{
* Tel.: +90 312290 2922; fax: +90 3122664065 .

E-mail address: RMartin@bilkent.edu.tr.
}

responsibilities in relation to public schools, in a way that may have unexpected affects on their society.

As evidence of the socially conservative nature of this society, these young women are often driven to and from university by their brothers; they seldom show their faces in public spaces; and certainly the domains of their mothers were primarily in the private spheres of homes. Yet, as anthropologist Unni Wikan points out in her account entitled Behind the Veil in Arabia: Women in Oman from three decades previous when writing about northern Omani women:

It soon became plain from the way these women walked, sat quietly, and talked, that they did not see their lives in terms of unmitigated subjugation-on the contrary, they questioned the merit and even the justice of ways instituted to enhance woman's life and freedom in neighboring Gulf states (Wikan, 1982, 5). Far from being dominated by male decision-making, the Omani women with whom I was working were learning to take charge of their lives while developing within the bounds of a secure social setting.

This paper brings to the surface evidence about the agency of young Dhofari women as they prepare to enter teaching careers, and considers directions for educational change that seem possible for these women within their protective and stable social situations. After establishing the nature and qualities of Dhofari women's agency within an open-ended service project, the implications of these women's agency on educational and curricular policies are briefly explored.

\subsection{Education in Arab states}

In examining the literature of comparative and international educational development at large, as published in journals for 
English speakers, neither the educational systems of Arab countries, nor contextualized discussions of social issues for Arab teachers are well represented.

Recent studies published at the micro-level of educationalsocial issues have portrayed Arabs from Israel (Abu-Saad et al., 1998; Weiner Levy, 2009) and the United Arab Emirates (Clarke and Otaky, 2006; Richardson, 2004). Weiner Levy (2009) investigates the "social exclusion, hybridity and alienation" of minority Arab women called Druze in Israel after they return home from getting a Western education for the first time. In contrast, the Dhofari women in this study did not leave home; rather, many aspects of a Westernized education were brought to them. Thus, rather than creating the ostracizing and alienating dynamics that form the underlying theme of Weiner-Levy's work, the Dhofari women in the present study are staying carefully within the established bounds of their traditional tribal and family life, while also stepping firmly into the emerging higher education environments that are being created locally for both women and men.

In examining teacher education in the United Arab Emirates, Schön's notions of reflective practices in education (Schön, 1983) have been examined within the context of values in an ArabIslamic culture. In contrast to a previous discussion by Richardson (2004), the findings of Clarke and Otaky (2006) suggest strongly that young Emirati women are "whole-heartedly embracing" reflective practices as pre-service teachers. Reading the two articles together is like seeing the flip-side of the same coin, juxtaposing the dualities of either being against or for the critical reflective capacities of Emirati women. In neither case was a range of skills of these Arab women clearly indicated. In the data collected by the present exploratory study of Dhofari women, they resemble young women around the world: some clearly struggled to think critically and reflectively within the English language and within their pre-service teaching practices, while others showed patterns of thinking distinctly outside of the proverbial box of the traditional, teacher-centered, lecture-based education with which they had grown up.

Studies published at the macro-level of social, economic, and demographic statistics (UNESCO, 2000, 2008) give an image of the Arab states as having enough similarity as to be able to analyze them as a cohesive group. The Arab countries as a region show steady progress in meeting "basic learning needs of all children, youth, and adults" (UNESCO, 2008), though participation in secondary education differs widely from country to country, with four Arab countries now providing free and compulsory secondary education. The Sultanate of Oman provides free yet noncompulsory primary and secondary education to its population (UNESCO, 2000).

\subsection{East meets West: socio-political trends in Arab education}

Two macro-level discourse studies that examine some of the political issues behind education (Grigorenko, 2007; Mazawi, 2002) suggest frameworks for interpreting educational change in the Arab states that move away from naïve conceptualizations of examining tradition in contrast to change. Both articles discuss the expansion of schooling in Arab states as a fact that needs explanation.

Grigorenko (2007) describes how the adaptation of Westernized schooling by Arab states has been triggered and reinforced internally, as these countries adapt it to their own needs. She notes that Arab countries have consciously emphasized their Arabic customs and language to distance themselves from Ottoman and European educational dominance $(2007,181)$.

In examining the discourse of the politics behind education in Arab societies, Mazawi (2002) asserts that interpreting school change in terms of the "redundant tale of traditionalism versus modernization" is an exercise of intellectual futility. He suggests understanding the nature of school change in the Arab countries lies in the "mediation of discontent" from within the local communities and public school systems themselves, citing examples from Oman and Yemen. To understand the expansion of education within the Arab states, Mazawi claims that it is essential "to gain insights into the multiplicity and interwoven complexity of voices within a given geopolitical region" (Mazawi, 2002, 69).

Based on the data from the present study, one could assert that young Dhofari women were showing a willingness to open themselves and their schools to the content and methods necessary for more learner-centered approaches to education. The youthful and idealistic voices of these young women whose skills, capacities, and ongoing decisions within and beyond the classrooms mediate the directional course of schools within their local area, which represents part of the tapestry of voices that make up Omani education.

\subsection{Indicators of human development in Oman}

Oman had a population of almost 2.5 million in 1999 with a population growth of $3.6 \%$, making it the fifth smallest Arab country in terms of population (UNESCO, 2002). The literacy rate at that time for men was $79 \%$ and for women $59 \%$; however, as public (or government-funded) schools in Oman were not started until the 1970s with the beginning of the reign of Sultan Qaboos bin Said, these literacy rates likely reflect the population above the age of 45 , many of whom did not have any formal education. With the national school system now in place, the disparity between male and female literacy rates will likely dissipate. As more women become literate, many are pursuing higher educations, and it seems reasonable to predict that they may begin to interact with society by seeking new opportunities to use their newfound literacy.

In contrast to the wealthy image of Arab states, Oman is not a country of the towering modern buildings that one sees in nearby Emirati cities (such as Dubai or Abu Dhabi). Much of Oman's shortterm oil wealth appears to have gone to hospitals, roads, and schools, as well as other supports for developing the infrastructure of the country and its local economies. As one policy writer describes:

In terms of political and economic development, generally speaking, Oman has accomplished as much or more than its fellow Gulf monarchies, despite starting from scratch considerably later, having less oil income to utilize, dealing with a larger and more rugged geography, and resolving a bitter civil war along the way (Peterson, 2004, 125).

Since the 1990s, the Omani government has worked to integrate women into both voting and elective positions in the nomination and election of candidates for the consultative council at the highest level of governance (Peterson, 2004, 133). A review of 2003 statistics about the employment of Omani women indicates that:

There were 598,000 employed men and 123,000 employed women, which translates to $17 \%$ of the female population. If we compare that figure with the $11.9 \%$ proportion of women in the labour force in 1990, we find that the progress achieved in a decade is considerable (Rassekh, 2004, 6).

Rassekh also describes the "outstanding position" of women in the Ministry of Education with many female teachers and administrative staff. In education, the advancing role of women was evidenced in Salalah by university staff who were a mix of both Omani women and men; all school principals whom I met in the 
mixed primary schools and girls' middle and high schools were female; and several women in influential positions at the Ministry of Education in the Dhofar region.

\subsection{The significance of agency among Arab women}

Since the Enlightenment, in Western schools of thought, debates have ranged far and wide about the concept of human agency and its usefulness to sociological and political discourse. As human beings, to what extent are we able to exert our own decision-making powers, to make intentional choices, to exert initiative? In contrast, to what extent does society exert its influences upon us? Do we shape the circumstances in which we live, or are we shaped by them? In this study, I turn to a reconceptionalization of human agency in which sociologists Emirbayer and Mische (1998) point toward the temporal dimensions of agency as developed in a practical-relational approach and away from the free will versus determinism debate. They examine how human actions are informed by the past, while also oriented to the present and future, defining human agency as:

the temporally constructed engagement by actors of different structural environments-the temporal-relational contexts of action-which, through the interplay of habit, imagination, and judgment, both reproduces and transforms those structures in interactive response to the problems posed by changing historical situations (1998, 970, emphasis in original).

Emirbayer and Mische posit three elements of agency in sync with the three dimensions of time: an iterational element draws on habits of the past; a projective element gives attention to imagination and future planning; a practical-evaluative element allows for judgment of immediate situational variables. Emirbayer and Mische call these three elements together as the "chordal triad of agency," and assert that all three are usually part of agency while one tends to be dominant. This conceptualization of agency underscores how human nature is not static across history, and that the capacity for agency varies as societies change.

This conceptualization of agency will help us to consider agency by looking at the metaphorical chord that is currently being heard among specific communities of women. Rather than seeing Arab women as being dominated or subjugated by their society, this paper examines their patterns of agency by looking at how their own discourse about actions resonates with different ways of considering the past, present and future. How did the Dhofari women in this study exhibit iterative, projective, or practicalevaluative elements of agency as they were learning to be teachers? It will be argued that the service-learning projects that they chose provided temporal-relational contexts that supported the practical-evaluative agentic orientation.

Given the rapidly changing political situations of early 2011 as citizens in many Arab countries (including Oman) rise up to challenge their governments, combined with the persistent though oft-unnoticed advances of women in the Arab world (UNDP, 2006), this study indicates that Arab women will have an impact on their society and on their evolving systems of education.

\section{Differentiating the Dhofaris within Oman}

\subsection{Geographic and social characteristics of the Dhofar region}

Describing the social relations and identity of women in a small local village of northern Oman (1982), Wikan states:

What Sohar lacks in physical, natural, and architectural beauty is amply compensated by the beauty of the manners of its people. Their grace and dignity are a source of continual human and aesthetic delight $(1982,28)$.

In contrast to Sohar's harsh geography, the southern coast of Oman prospers from a microclimate that catches the Arabian Sea's monsoon for two full months each year, creating greenery complete with waterfalls. Wikan's description of the Omani people does, however, resemble frequent comments by visitors to the Dhofar region as well.

The only large city in the Dhofar region is Salalah, with a population of about 150,000 , with many Indian and Pakistani expatriates in the labor force. Currently, Indians along with Egyptians and Jordanians serve as school teachers; however, with the Omanisation process implemented by the government, public school teaching is among the professions for which the hiring of expatriates is being phased out. These facts influence the present research in so much as many English teachers of the past generation were not local Omanis and brought with them many of their own traditional approaches to education.

Historically, living in extended tribal families, Dhofaris have supported themselves by trade and cultivating the age-old frankincense sap into perfume and incense, for which the region is especially well known. In addition, there is also much herding and fishing along the coast. Williamson (2006) distinguishes four cultural groups living in Dhofar: The African-Omanis and the Bedouins are the two smallest groups; the Bait Kathir (or "town Dhofaris") is a large group of Arab-descendents who tend to be merchants and businessmen. The largest group are called Jebalis, often described as "sharp, spirited, friendly, proud, and stubborn" (Williamson, 2006, 14).

Trying to interpret this study as the voices of Dhofari women is laden with the problem that the Dhofaris are not a unitary group. Although all youth are now going to school and being educated in Arabic from the first grade, which unites them in some ways, their social and cultural roots make them notably dissimilar.

\subsection{Dhofari women in transition}

Picnics are a popular social event held throughout the year, especially during the monsoon season, often as spontaneous gatherings along rocky coasts or sandy beaches on Friday afternoons. Now, as in previous generations, picnics involve those from within the same tribe. As the university introduces new cross-tribal social situations, young women go on picnics with new female friends who they meet through university programs as well as in schools. These situations present lively informal social opportunities. Of course, the honor and dignity of the young women are still closely guarded, and only when fathers know the reputation of the other women in a group do they allow their daughters to participate in such events. Even daughters in their mid-20s, until they are married, must ask permission from their fathers to do anything outside of the home.

The covering of women's hair and wearing of the veil (burqa) is often discussed as a sign of repression in Western societies. However, in Oman, this issue was rarely discussed as political or repressive except by foreigners; locally, it was simply required by all tribes for feminine modesty. Plus, as one of the research participants added when reviewing this report, "it gives us the feeling of security and safety" (email, dated November 4, 2010). When younger students in schools and at university began wearing shaylas (scarves around their head) more loosely, it was not seen as a political assertion so much as the youth showing their expressiveness. The general acceptance of the long black abayas (black robes worn in public) could be viewed as an example of how they follow local customs while making stitching and fabric alterations to fit their widely varied personalities. 
As for wearing veils in middle schools and high schools, there is no need for veils as the schools are run and operated completely by women. An interesting trend began several years before I arrived; women can no longer wear veils in colleges (post-secondary institutes), universities, or governmental departments. Although I found no news articles or official documents on the Internet about this matter, while living there, I was informed that the Sultan had declared officially around 2003 or 2004 this prohibition of wearing veils at university. Apparently, this was a novelty in Arab countries; though, obviously seeing facial expressions makes learning and teaching much easier given the interpersonal dynamics involved in student-centered classrooms. Another consequence of this policy is that university women are gradually becoming more comfortable with being seen by male peers and male teachers. At the time that this change of policy was implemented, however, I was told that some young women showed much agency in their zealous protestations.

A final comparison is worth noting between Dhofari women and women of the Harassi pastoral tribe of central Oman. Sociologist Dawn Chatty characterizes the Harassi women as "harbingers of change". With over 10 years of field experience in working with social and human development in central Oman, Chatty uses thick ethnographic description to illustrate Harassi women's independent personalities, strong wills, and collaborative approaches to working with their husbands. Aligning with the findings about women's agency in the present study, Chatty concludes:

The fact that education now fully extends to both girls and boys is a tribute to the spirited efforts of a handful of women and their supportive spouses. Harassi women, through a concerted cooperative effort to help themselves and their daughters, really have been able to demand formal schooling. At another level, this action clearly reveals that women as they view themselves-and as their men regard them-are actors, with the power to determine their own needs and those of their families and the authority to control their lives and those of their children (Chatty, 1996, 163).

Although these examples may seem as isolated events, the number of examples between Chatty's descriptions $(1996,2000)$ and my own observations of Omani women in Salalah are plentiful, illustrating how women show their firm resolution in ensuring their own education and that of their daughters.

\section{Research methodology}

\subsection{Discourse analysis of essays, with ethnographic observations}

The present study uses discourse analysis (van Dijk, 2008; Paltridge, 2006) to examine individually written reports about group projects completed at the end of the pre-service teachers' teaching practice. Some ethnographic descriptions are also included of observations and situational dynamics that help to interpret these reports.

In May 2008, signed informed consent was given by 49 of the 52 pre-service teachers for analyzing specific data sets to be used for the purposes of advancing research about teacher learning in Oman. The two male students in the cohort were not asked to participate in the study as it was felt that gender differences are still so prevalent in the culture that a separate study would need to be done for analyzing their views. By verbally reviewing a written research summary with each participant, agreement was obtained one-by-one to insure that each understood the purpose of this potentially long-term research project.

To the extent possible, exact words and phrases used by the preservice teachers are analyzed in two ways. Words and phrases are analyzed for their intersubjective meaning with attention to contextual details of actions described; other quotations are analyzed more broadly to convey individual, divergent perspectives. As the researcher, I also exercise my interpretive voice to highlight social or linguistic trends observed in the cohort at large.

Research participants were given a chance to select their own pseudonyms; however, in some cases, they expressed no preferences. A combination of Arab and Western pseudonyms are used in an effort to help readers feel a stronger sense of both the similarities and divergences between how these Dhofari women approach their choices versus how Western women would. (Some self-selected names such as Dream, Moonsister, and the Departure of Longing were not used due to connotations that Western readers might unconsciously assign-an unfortunate example of what is lost in translation from Arabic, local languages, and Dhofari culture to English language and Western culture.)

\subsection{TEFL program context}

The program that these pre-service teachers were completing was a one-year teaching diploma specializing in curriculum and instruction for English language teaching for middle and high school teachers. In the first semester, they completed six curriculum courses of 15 weeks each; in the second semester, they completed two additional 15-week courses along with supervised teaching practice in schools. From February through May of 2008, they completed their required teaching practice with each assigned to one school, placed across five Salalah secondary schools. This study examines essay assignments completed in coordination with their teaching practice, which was supervised by me in coordination with head English teachers at each school.

\subsection{Data collection and analysis of school contribution projects}

During April and early May 2008, the pre-service teachers were asked to work in teams and complete a school contribution project. The purposes for this project were multifold: (1) to encourage the pre-service teachers to consider student needs beyond the classroom; (2) to encourage observations about the social aspects of their own learning in contexts that were likely to be personally meaningful for them; (3) to compensate for the limited number of teaching hours that they could complete in each school; and (4) to promote better relations with local schools. After completing their school contribution projects, they were required to submit a twopage summary about what they had learned from the process of working together to help students outside of classrooms.

The assignment emphasized social and emotional learning, as well as cooperative learning; in the previous semester these were aspects of Westernized curriculum theory that resonated most strongly with the pre-service teachers. These school contribution projects are considered as evidence of varied types of agency taken in public settings and the elements of their own actions that these young ladies are willing to describe afterwards. The choices made and discourse used to discuss their choices highlight how they see their own agency and how they frame their actions as an accomplishment for their society and/or for themselves.

As experiential out-of-class learning is not (yet) a common feature of Omani schools, it was also notable how some groups chose projects that fit into current conceptualizations of school learning, while others were more outside the box in their approach to the assignment itself.

\subsection{Researcher positioning as an outsider}

Of course, it is important to note the particular voice and role of myself as the researcher. Clearly from my face, dress, name, and 
lack of basic language skills in Arabic or other local languages, the Dhofaris were aware of me as a Western foreigner immediately. Yet, as a woman who had no agenda other than getting to know them and their culture and offering what knowledge I had of constructivist approaches to classroom teaching, I seemed to have a special, non-threatening position in their society. Given my academic background combined with my interest in learning a bit of Arabic, they held me in an esteemed position. Like other foreigners, I was not expected to dress as an Omani; dressing conservatively out of respect, I wore long skirts or trousers, and shirts that were conservative in style.

Still, I was not one of them; not only was I not Dhofari, I was not Muslim either; yet they had a simple acceptance of me that I found remarkable. Unlike Western men, I had occasional windows into the lives and homes of Dhofari women that showed their welcoming of me in their society, along with unique views into girls' schools and classrooms.

To compensate for my outsider perspective, care was taken to send this manuscript as it develops to several former students and Omani women for their comments and feedback. These participant checks pointed out where I had over-generalized about the uniqueness of the young women or policy issues, and they suggested more practical ways in which to interpret an issue (which were incorporated into the current version of the manuscript). The limitation of these participant checks as with other such ethnographic studies is that participants sometimes hesitate to comment very much about academic writing, which often feels outside their realm of expertise. Also notable for reasons stated in this report about the characteristics of their agency, Dhofari women are not likely to voice strong disagreement as their mode of agency for change; it's simply not their style. Perhaps in the future, as masters' degrees are offered in this field, Dhofari women will begin to conduct more of their own critical research.

\subsection{Limitations of this study}

In addition to the limitation of the necessarily etic views of an outsider (Headland et al., 1990), two other limitations deserve mention. First, the study analyzes a required assignment, which may have skewed the reports themselves and the subsequent interpretations of their meaning because clearly the young women were aiming to please me as their instructor/supervisor. However, even given this limitation, the varied forms in which they tried to please are worth noting. Still, ultimately, the reports should be considered from the standpoint that they were written for a required assignment to be reviewed by an outside Western woman.

A second notable limitation is that this discourse analysis reveals patterns concerning the student-teachers' newfound agency as they were learning to be teachers; however, writing about their own agency was not the purpose of the assignment. Thus, the analysis examines implicit as well as explicit meaning structures embedded in the discourse of their writings, a process imbued with potential for misinterpretation. Nonetheless, I precede cautiously and with the knowledge that participant checks help ensure that their perspectives and priorities are represented, and that further discussions with the Dhofari women will likely arise in the months ahead as I return in person to talk with them about their evolving practices and problems in schools.

\section{Analysis: Dhofari women take action in education}

\subsection{Theme of agency across school contribution projects}

For the school contribution projects, the pre-service teachers put themselves into seven project groups; five groups were self-selected according to the schools in which they were working, with projects primarily for helping students with English outside of classrooms. Two projects were organized for the university's Cultural Week for considering the challenges of learning to be teachers; these were primarily for a public audience, with a focus on the interests of local English teachers. Three of the five schoolbased projects were Open Day activities; while two were projects developed seemingly independent of activities offered previously by local schools.

This discourse analysis summarizes examples found across these service projects in terms of their orientations toward agency, as indicating iterative, projective, and practical-evaluative elements (as defined by Emirbayer and Mische, 1998) in how they describe their own decision-making processes. As Emirbayer and Mische point out, these dimensions are not mutually exclusive as categories; but rather, that human actions involve varying degrees of all three as a "chordal triad of agency, within which all three dimensions resonate as separate but not always harmonious tones" (Emirbayer and Mische, 1998, 972). As a whole, this analysis points readers toward the capacity of these Dhofari teachers-intraining in the context of service learning projects toward an orientation of agency that has a strong practical-evaluative element. In addition, this practical-evaluative element weighs heavily toward decision-making in which social harmony is often given implicit priority over personal aggrandizement. The overall effect that this creates is that young women are learning to take agency in ways that are not always easily recognizable as the more assertive forms of agency common in Western cultures.

Quotations in this section come from the student-teachers' reports about their service learning projects that were submitted in May 2008, and from cited pages of Emirbayer and Mische (1998).

\subsection{Iterative dimension: agency that draws selective attention from the past}

When making routine, unreflective decisions that are based on the past, one would tend to regard such as non-agency, hardly worthy of being called conscious decisions, due to the role of habits, pre-conceptions, and schema that are derived from past experiences. Thus, the tendency is to see such actions as limiting the choices of the individual to routines and pre-established patterns. While Emirbayer and Mische would not likely disagree with the limitations of this orientation, they nonetheless point out that even decisions oriented toward future planning or immediate situational factors are:

...deeply grounded in habitual, unreflective, and mostly unproblematic patterns of action by means of which we orient our efforts in the greater part of our daily lives. We have settled upon the unfamiliar term iteration to describe such activity precisely because the dimension of agency to which it refers is the most difficult to conceive of in properly agentic terms (Emirbayer and Mische, 1998, 975).

In looking across service projects, three pieces of evidence stand out that concern this iterational orientation for some, though not all, student-teachers.

The first piece of evidence is that three of the seven groups chose to develop their projects within the familiar backdrop of Open Days, an already well-recognized practice within Omani schools. Open Days involve a full morning and afternoon of cultural activities, games, competitions, food sales, and creative poster displays in which students share their learning with a broader community. The people invited to participate may include teachers, ministry of education officials, university personnel, or family members, and of course students and teachers. Sometimes 
Open Days are coordinated by administrators, sometimes by teachers, sometimes by students.

Open Days seem to lend a sense of stability and order to what teachers-in-training assume will be beneficial to students, so much that most of the papers about Open Day projects did not even give a rationale for why an Open Day project was selected. Sharhath alluded a bit to a rationale when she discussed the importance of creating a "caring learning environment" that would benefit students and support them in becoming "competent members of society." Farasha referenced a similar point with emphasis to the broader purposes that, "The schools of Oman in general need this sort of project. It gives the students with talents in English the opportunity to present themselves."

The second piece of evidence of an iterative orientation toward agency was the inability of almost one-third of the project reports to describe the reporter's own learning within the project, even though that was an explicit aspect of the assignment. Many student-teachers seemed unable to describe their own learning beyond vague statements that their participation had made them "happy and comfortable," or that it was "beneficial" for learning to work as a group. Although they were able to summarize main ideas from the texts about social and emotional learning and/or cooperative learning, they were either unable or unwilling to look at specific incidents within their experiences. In essence, I would characterize their papers as having selective attention to what they were expecting to observe, recognizing types of typical predefined activities with an inability (or unwillingness) to summarize new ideas or issues that may have come into their awareness as they were completing their service projects.

In many cases the pre-service teachers who struggled most with the self-reflective aspect of writing their reports were the same pre-service teachers who initially found the greatest difficulty in handling their classrooms. Their capacity for taking action seemed as an inhibiting factor, seemingly related to this refusal to examine themselves, introspectively or retrospectively in the context of particular situations, in ways that might put themselves at or near the center of the complex dynamics of student learning. They often labeled this phenomenon as "shyness", and there was a group every semester who struggled with showing enough confidence both inside and outside the classroom to be able to command the attention of the often vigorous and sometimes commandeering teenage youth.

The third piece of evidence was the maintenance of their expectation toward the inclusion of God/Allah within the descriptions of about one-fourth of the project reports. In reference to their Muslim heritage and customs, special service learning projects (that were one-time events, rather than weekly help for students) were sometimes described as beginning with a recitation of a verse from the Holy Quran, "one of the sayings of the Prophet Mohammed, PBUH" (Peace be upon him). Another pre-service teacher discussed helping each other for the reason of a "good reward from God." Reference to God in Dhofari students' writings is so much more frequent than one finds (from my experience) in American universities where I have studied and worked that it seems worth noting as a iterative element of agency that students seem to use to add order and stability within the introduction and interpretation of new events.

\subsection{Projective dimension: agency that looks to the possibilities of the future}

When examining the structure of projectivity within the concept of human agency, Emirbayer and Mische describe how it may draw on the past, yet focuses more on a trajectory in which "thought and action may be creatively reconfigured in relation to actors' hopes, fears, and desires for the future" $(1998,971)$. This element of agency showed itself whenever the pre-service teachers discussed their beliefs about their students' desires for wanting to participate, or their fears of participation.

In addition, three groups chose to create service activities that were new for the schools in which they were working, so their reports provide a narrative reconstruction of their goals and intentions in light of what they had anticipated.

In selecting student participants for English Open Day activities, Darina explains that teachers helped them to choose students who were "very active" and had "the desire to make it with a beautiful feeling." Darina's choice of the word "beautiful" is one of several words in Dhofari English vocabulary that I feel certain did not come from any textbooks at the university; rather it seemed as a distinct quality often used to elaborate on issues, a quality that stood by itself and needed no additional explanation in their decisionmaking. It may be akin to what we would call having a good attitude in Western education, though imbued with other layers of implicit meaning about a goal for encouraging the subtleties of internal beauty.

Another group of pre-service teachers offered an elective lunchtime English speaking course to high school students who "have the desire to speak English during the break." For them, the desire of students was pivotal to how the project was described. In an extra report summarizing their project, the group members collectively stated that the purpose of this speaking class was:

to reinforce productive skills of students, improve their selfconfidence to speak well when they face daily situations, and to be more daring with any subjects, and talk about their opinions freely without any confusion or fear.

Within this project, the reports used two distinct rationales as their organizing frameworks. Some structured their individual reports in terms of students' needs in relation to the school and/or social context. Two others examined a changing belief within themselves, acknowledging not having understood a major issue previously-thus revealing their personal fallibility. Essentially, they were engaged in what Emirbayer and Mische have called "aniticipatory identification" (1998, 989)-evaluating the past in order to create a future identification about the sort of character that they wanted to help their students to develop.

As an example of the pattern that emphasized the learning needs of students in relation to society, Sharhath considered individual students and how they were "suffering" in the classroom. Along with some of her peers, Sharhath seemed especially taken by a report about social and emotional learning that,

claims both parents and teachers need to encourage students emotionally and physically in order to become good citizens for their country [her interpretation of the report].

Sharhath quoted the report as emphasizing how education needs to teach "the test of life, not a life of tests" (Stodden et al., 2003), a quotation that had garnered much attention several months previous in a course discussion. In making sense of these issues for herself, Sharhath claimed,

In Oman's society there are some students who suffer from social and emotional problems whether by external influences (teachers, families and peers) or by internal influences (student himself). I observe this in my family and in the school where I taught.

Here, Sharhath shows a willingness to observe something less than positive. Rather than claiming that schools or family situations are all good, she admits that, "there are some students who suffer." To 
give explicit support to this point, she then describes one student about whom she was particularly concerned:

She keeps silent all the time. She did not do anything; she just put her slim hand on her cheek and listened to us. Actually, I didn't know why she had joined this class!! One day, I was close to her and I asked her, 'What's wrong dear? Why don't you share?'

She looked down and replied, 'I understand what you discuss, and there isn't any need to talk.'

'Why? This is your chance to improve your speaking,' I replied. She told me that everybody hates her, and her peers laugh at her when she speaks in the class because she does not speak clearly.

Rather than ignoring the feeling stated by the girl, Sharhath acknowledges it; then, she describes how she attempts to control her nervousness as she asks other students to stop laughing while their friend is speaking. From that day, Sharhath claims to notice that this student begins to participate.

As a whole, Sharhath's analysis of this action and its consequences show her own experimental enactment of taking on new responsibilities for supporting students more actively within the peer pressures of a classroom. For a beginning pre-service teacher in a society that has strongly supported teacher-centered approaches, such a social realization by standing firmly in herself to change classroom dynamics is significant to notice in her discourse. Experimental enactment is described by Emirbayer and Mische as being at a crossroads between the future and the present, where individuals "try out possible identities without committing themselves to the full responsibilities involved" $(1998,990)$.

In contrast to Sharhath's focus on social pressures faced by students, Jamilah's discourse reveals a self-awareness of her own changing beliefs. As with Sharhath, we may interpret Jamilah's discourse as how she is defining her future identity as a teacher, with emphasis on how she begins to see the students in a new way:

Before I had done my project, I thought that the main problem of the bad level of students in English was because they don't want to learn, and that they don't take the available chances to improve their level in English. Here, I was mistaken. Everyone says to me that students don't want to learn, they just want to have a fun time and enjoy escaping classes. Here, they forget that students in every part of the world need only a hand to guide them to what they should do. That is what I have learned; I have become more aware of my students and their needs and their fears. How I help them is the question that I think of all the time. Therefore, I tried my best to help my students through giving them open spaces to express ideas and thoughts. Moreover, I learned that students want to learn, and I have seen that because of the big number of the students who came to the class even though it was break time..

Although the above passage is written completely in the past tense, here I am claiming that in terms of Jamilah's development as a teacher, it is an indicator of a retrospective-prospective process. She is describing the near past as a tool that is also beginning to define her own expectations and identity as a future teacher. With a starting point of her own mistaken belief, Jamilah softly points out the negative preconception of many teachers in Salalah schools about students; indeed, teachers often spoke of Dhofari students as being lazy and stupid. Rather than blaming or criticizing teachers, Jamilah almost brushes it aside as she states, "Here, they forget that students. . .need only a hand to guide them..." as she clearly projects forward to the needs of students that should be given more attention.

In a society where it not deemed admirable to question the future (as that is God's realm), the projective dimension seems to be the most tacit of the three temporal relations of agency. Also, to project something different in the future requires some critique of the past, and this is done only with great caution. Jamilah attributes the less positive attitude of teachers to their forgetfulness; thus, she quickly returns her attention to students' needs and does not get caught in a discussion about the problems of teacher attitudes. Like Sharhath, Jamilah exhibits a projective dimension of agency in a subtle way through the clarity and strength of her rationale for why these socially accepted beliefs about students are simply not true, thus implying that change is needed.

\subsection{Practical-evaluative orientation: agency that focuses on situational variables}

In their self-labeled relational-pragmatic approach to examining agency, the third dimension of agency that Emirbayer and Mische (1998) proposed is that of a practical-evaluative orientation. From Aristotle to Kant to feminist theories, this dimension of agency has been examined as the one by which actors give foremost attention to the immediate judgments necessary for evaluating particular situations. Emirbayer and Mische (1998, 997) consider the structure of this dimension in terms of problematization, decision, and execution of the decision, along with how the actors characterize and deliberate over the problem. In terms of its significance, Emirbayer and Mische claim,

By increasing their capacity for practical-evaluation, actors strengthen their ability to exercise agency in a mediating fashion, enabling them (at least potentially) to pursue their projects in ways that may challenge and transform the situational contexts of action themselves... (1998, 994, emphasis in original).

In this snapshot of a short period in time when these young women were engaged with their service learning projects, many of their project reports indicate a dominant practical-evaluative orientation. Of course, the task of developing a service learning project was a relatively ambiguous assignment that may well have lent itself to giving increased attention to the immediate needs of students and the school in which they were doing service. What is interesting, however, is the manner in which these young ladies reported their decision-making processes.

\subsubsection{Learning from students, whose spirits are sometimes hidden}

Khadija frames her report around her own learning from a student who chose to participate, who was poor in English and not recommended by teachers:

.. I was astonished by her ability to act as if she is not the girl I know, even my friends felt the same, because she really acted as if she was a professional actor.

When Khadija claims that, "even my friends felt the same," she implies that her observation was supported by others, though not necessarily by the school teachers. Khadija reiterates how this girl had volunteered, even though none of the teachers had recommended her. Then, in a typical eloquent and generalizing style of Dhofari discourse that often frames situations in the most positive light, Khadija explains why the teachers may have overlooked this girl:

..they forget that students have the spirits that can change the whole world but they don't know that they [the students] keep these spirits hidden behind the wall of being good in the class. Khadija is noticing something in direct contrast to the trained teachers of the school and searching for a way to make sense of that. As Jamilah had also done, Khadija gently frames her view 
about teachers by simply stating in a non-accusative way that "they forget..." While drawing on both future and past dimensions, what distinguished Khadija's discourse from Jamilah's similar claims was the detail with which Khadija characterized the present situation in relation to a particular student and the challenging situation that student presented due to her unique character.

\subsubsection{Minimizing reporting of agency to give attention to the group}

In helping to facilitate a friendly competition for English Open Day, Farasha was exceptionally active in developing the technicalgraphical aspects and content of an interactive computerized game, which she used as a moderator of the competition; however, she references this fact only in passing.

Farasha's discussion about social and emotional learning focuses on what she was learning from peers when angry tempers would occasionally surface. Although Farasha had demonstrated much initiative in this project, the discourse of her report minimized the significance of that role-a level of deliberation and execution of many small decisions that might have separated her from her peers.

Fatima served as a behind-the-scenes helper, and she starts her report by describing the project as "a great achievement that the university trainees did." For Fatima, the day's activities were organizing the competition, showing students' work, and how the trainees organized invitation cards, appreciation certificates, gifts, and a buffet for guests. The practical-evaluative of Fatima's agency was evidenced by the focus of report on how guests were invited and treated; the "achievement" itself was framed foremost in terms of the whole group, not herself.

\subsubsection{Acknowledging intense feelings while avoiding conflict}

Darina and Farasha discussed how some peers became angry when school administrators changed the event date at least twice, interfering with the designing and printing of formal invitations. For them, the problem was framed as an issue of self-management; Farasha states:

All tired and angry feelings were just between us, we did not show them to others. We stacked together to accomplish the mission.

Here, agency relates to deliberating on what they are doing by how they worked together in spite of a challenging situation. This tension with school administrators was referenced only by two of the eight working on this project, and only for showing how they were learning to work together. Their descriptions indicate an importance placed on conflict avoidance through careful monitoring of emotions, showing negative emotions judiciously only to those with whom it is appropriate.

\subsubsection{Discovery of "other sides" of self: responsibility, commitment, and patience}

Myra and Monteha both claim that this was their first experience (ever) in which they were responsible for coordinating a relatively complex set of activities. Myra discusses the "sense of responsibility and commitment" that this gave her, combined with "discovering other sides of my personality," such as "having faith and trust in others and being able to depend on them," as well as working cooperatively-“even when we were tired." This may seem a minor detail to the Western reader, yet in Dhofari culture, it is common to stop and rest when one is tired, not to push onward. Such notions as timelines and schedules are relatively new in this culture.

Monteha describes how the experience helped her to learn more patience, even in the face of difficulties. These comments from Myra and Monteha were interesting as I'm sure that both these young women had many responsibilities in their homes-where they were often learning of commitment and patience, so it was as if they were separating their new public-work selves from their family identity.

\section{Discussion: Dhofari women's agency and policy implications}

Given the confines of their school contribution projects, the preservice teachers in this study put themselves into three types of groups: (1) Groups that designed Open-Day activities, choosing a familiar out-of-classroom learning context already in place within the school's social structure, (2) Groups that designed activities to help students improve their English outside of the classroom, within structures that did not already exist at the school, and (3) Groups that upon gentle prompting coordinated a discussion panel or poster display for an audience of peers and public school teachers. This study used discourse analysis to examine how these young women described their own activities within these school contribution projects, as an illustration of three temporal dimensions of human agency. Emphasis is given to how they were learning to make choices as members of their local community in ways that illustrate their willingness to both stay within and move beyond pre-determined social structures.

\subsection{What do these patterns of agency indicate?}

Again, it needs to be emphasized the three temporal dimensions of agency are not empirically separate but that one or another tends to have dominance within this "chordal triad" of agency (Emirbayer and Mische, 1998). The purpose of making this analytical separation of the three dimensions is to consider the extent to which they are resonating in a harmonious chord, and which dimension appears most dominant. The form of the agency taken by these young women when given opportunities to help the younger generation may give clues about how they will respond to the shifting career opportunities around them.

As such, it is notable that the iterative dimension that relies more heavily on habits of the past was notable among about onethird of the sample. It was evidenced by some project choices, by their inability to de-stablize their own self identity to examine more closely particular incidents of experiential learning, and frequent reference to God as a familiar, reverent element that they add to the introductions of one-time projects. In contrast, the projective dimension was notable only in a few reports and then only when examining the subtle implications that pre-service teachers made for needed changes. The changes noted were in the direction of teachers needing to understand students' fears of speaking in class and willingness of young people to participate when given the proper encouragement.

The strongest dimension among this sample of pre-service teachers was the present-focused, practical-evaluative dimension of agency. About half of the sample reported their projects in a way that showed a brief characterization of the problems faced in selecting and following through with a project, as well as the deliberations necessary for making choices and the emotional engagement required for understanding the difficulties faced. There was a tendency to often focus more on the execution of decisions rather than the problems; when problems were mentioned, it was usually done in a way that minimized the role of the individual as well as conflict or disagreements, while drawing attention to the perceived successes of the group.

One of the questions for future research posed by Emirbayer and Mische was, "How do different temporal-relational contexts support (or conduce to) particular agentic orientations?" $(1998,1005)$. If we consider service learning in teacher education as a temporal-relational context, this study indicates that in rural Dhofari culture such an ambiguous and socially oriented 
assignment lends itself to a potential for pre-service teachers to move toward the practical-evaluative dimension of agency. However, that potential may or may not be actualized depending on the strength of the iterative note of agency in how the young women conceptualize their activity.

As a whole, these patterns of agency show how young Dhofari women were approaching new situations from distinctly different positions. As they participate in these and other public school events, such patterns will likely continue to influence their participation and styles of agency. Given their social awareness in observing how others are responding to them, their continued observations of how others respond may weigh heavily in their choice of pursuing new and challenging activities versus expanding current practices.

\subsection{Qualities that distinguish Dhofari women and their agency}

In addition to the three themes of agency explored, this discourse analysis also indicates varied conceptual frameworks of how Dhofari women approach new responsibilities and construe the benefits of collaborative projects to themselves, to their students, and/or to the greater community. Their similar yet distinctly different descriptions illustrate how they each conceptualized a project in its aftermath while demonstrating their own agency concerning activities to which they had contributed.

Table 1 summarizes common qualities, or personal characteristics, as revealed in this analysis, that may affect the patterns of agency that these women were learning to take. Moreover, these qualities may also influence how Westerners interpret and make sense of Arab women's actions. As Westerners are continually brought into work with the young Omanis for pre-service training, many misunderstandings could be reduced by cultural training sessions that help newcomers to understand the Omani women more fully on their own terms, rather than making unwarranted judgments based on our own cultural assumptions.

Dhofari women are not from a cultural background of rugged individualism that oft characterizes Americans, Australians, and other Western approaches to self development. Therefore, how they learn to take responsibility and exert agency does not align conceptually with the active and individualized decision-making or action-taking behaviors that are valued by Western standards. Yet, these women were clearly taking many actions while working within the new social and education system, when given the opportunity.

In addition to the somewhat modest, perhaps even humble, qualities listed in the Table 1 , several women in this sample were outspoken and ready to take action in ways that any Western woman might describe as assertive, spunky, or even forceful. Such spunky exceptions to the norm were accepted gracefully by others, and are an interesting anomaly in the society, worthy of future case studies, but beyond the scope of this analysis.

\subsection{Taking responsibility or assuming duties?}

Brief referencing to the significance of God was prevalent in these and many other assignments from students. This is worth noting in so much as these young women are learning to take action, coordinate, organize, and do things that involve both individual responsibility and teamwork. Yet, for them, agency was not just about themselves, their peers, or the students whom they were serving; in addition, there are continual allusions to God, or Allah, as a source of power greater than themselves.

Understanding the significance of this issue by Westerners working in Arab countries cannot be underestimated when trying to uncover the nuances and subtleties of women as active agents taking on new responsibilities. Indeed, are they taking responsibility, or are they assuming a duty (a more common word used by them) that they feel is given to them by a higher power? An occasional conversation about such matters with university students usually informed me that they felt some balance of both involved in their actions.

This analysis leaves us with questions such as: How do their varied understandings about their relations to God affect the kinds of responsibilities and duties that they take or are given to them in their society? Is the nature of agency changing in their own minds as Western ideas and technology enter this rural area of Arabia? This paper cannot answer such questions, but points to the significance of asking difficult questions that research alone may never be able to answer.

\subsection{Policy tensions for curriculum implementation}

During the latter part of the 1990s, the Oman Ministry of Education began implementing increasingly student-centered approaches within their "ambitious" Basic Education curriculum, "aiming to develop life skills through communication and self learning" that included a new English curriculum (Wyatt and Atkins, 2009). The implementation of this curriculum, however, often involves an assumption that new teachers need carefully structured guidelines, rules and procedures to follow. The Basic Education teacher manuals are so detailed that they could be described as a teacher-proofed curriculum explaining exactly what to do and how to do it. For some new teachers, this seems valuable as they are nervous in their initial months entering classrooms, and there often weren't enough experienced mentors to guide them. Still, there is some lack of allowing and encouraging young teachers to develop their own critical thinking and facilitation skills in relation to the curriculum.

Table 1

Qualities of agency that appear across individuals.

\begin{tabular}{|c|c|c|}
\hline Common quality & Description based on... & Situations in which quality was exhibited \\
\hline Attention to social presentation of self & $\begin{array}{l}\text { Several reports discuss self presentation and learning to be daring } \\
\text { as goals for student learning; others take less visible responsibili- } \\
\text { ties in their own social presentation. }\end{array}$ & $\begin{array}{l}\text { How they frame what students need to learn; } \\
\text { choices that they make in project participation. }\end{array}$ \\
\hline Avoiding social-emotional conflict & $\begin{array}{l}\text { Gentle acceptance, almost non-questioning of current practices: } \\
\text { "they forget..."; acknowledging in a non-accusatory manner that } \\
\text { older teachers may do things they don't like; avoiding direct } \\
\text { judgment. }\end{array}$ & $\begin{array}{l}\text { When emotions are tense, or in a potential } \\
\text { disagreement with current teachers or adminis- } \\
\text { trators. }\end{array}$ \\
\hline Struggle to see self as an individual learner & $\begin{array}{l}\text { Just over half of the sample could describe their own learning from } \\
\text { new experiences; others were excessively vague on this point of } \\
\text { the assignment. }\end{array}$ & $\begin{array}{l}\text { Specific experiences in which they are learning in } \\
\text { relation to others. }\end{array}$ \\
\hline Tendency to exaggerate or overgeneralize & $\begin{array}{l}\text { When they notice something new about others, descriptions often } \\
\text { show a "beautiful" or "astonishing" flare. }\end{array}$ & $\begin{array}{l}\text { When emphasis or eloquence is needed to } \\
\text { underscore a key point. }\end{array}$ \\
\hline $\begin{array}{l}\text { Minimization of own role in accomplishing } \\
\text { a task }\end{array}$ & $\begin{array}{l}\text { Minimizing personal efforts as seeming less significant than } \\
\text { working in relation to students and peers; showing real humility. }\end{array}$ & $\begin{array}{l}\text { When they do something that makes them stand } \\
\text { out from their peers. }\end{array}$ \\
\hline
\end{tabular}


Missing from the discourse about policies for curriculum implementation was a careful consideration of how new teachers could be given opportunities to exert agency and learn of responsibility. For example, I heard assertions by Dhofari teacher supervisors about the importance of insisting that teachers follow the manual. These assertions led to tensions in relations between teachers and the Ministry of Education, with a lack of clarity about the amount of authority that the Ministry needed to exert. As Omani women were trained locally, some expressed a sense of powerlessness to question or stray from the step-by-step curriculum. As new teachers, they hesitated to voice such tensions.

Following are a few implications for curriculum implementation and pre-service teacher training based on the discourse that unfolded from the school contribution projects that were the focus of this study:

(1) More experiential learning could be incorporated into the university years, in which students develop service projects by working in the community. Such hands-on learning through cooperative activities develops their sense of responsibility while learning to interpret social, political, and educational issues from their own frames of reference.

(2) Within teacher education, new instructors, trainers, and teacher supervisors could use explicit encouragement to move against old lecture-centered trends for training teachers, and to use active learning techniques for allowing women (especially) to exert their agency while working with others. This can be done by giving choices within assignments as well as through facilitating group discussions that seek out multiple perspectives.

(3) Activities designed especially for cultural and intercultural awareness could help expatriates (hired to work in a culture that is unfamiliar to them) to see more clearly how Omani women are learning to take power and responsibility, while exerting patterns of agency that may look different from the West or even different from other Middle-Eastern and Eastern cultures too.

One encouraging event that I attended during my final months in Oman was a training session for new English teachers in which the teachers were invited to facilitate meetings about what they were learning in their classrooms. Based on the results of this study, more events like this could help to give young teachers a greater sense of their own power and responsibility.

\section{Conclusion}

In the overall framework of international education and human development, what few formal studies exist of education in the Arab world (as written in English medium journals) have tended to be more at the macro-level of discussion. Looking at trends from UNESCO reports $(2002,2008)$, there is a vague understanding that improvements are being made within Arab schools; and that in some Arab countries such as The Sultanate of Oman, women are being integrated into the workforce as part of the driving force of change. How those improvements are being implemented vary widely from one country to another. Furthermore, even the Arab Human Development Report of 2005 (UNDP, 2006) that focused exclusively on women in Arab society did nothing to indicate what was happening in schools beyond a brief analysis of textbooks. This study has attempted to begin filling the void of micro-level and qualitative research about regional areas of the Arab world with details about how young Dhofari women are exerting their voices and learning to exert agency as teachers-in-training.

The question of whether education systems follow tradition versus change is much too simplistic, and as we examine the kinds of changes that are unfolding, we need to consider what Mazawi
(2002) described as the "multiplicity and interwoven complexity of voices." However, while Mazawi argues for examining the "mediation of discontent," this analysis and my own observations from three years of working in southern Oman, indicate that the many Dhofari women show little inclination of voicing discontent. They are situated in a safe and secure social environment, and seem to understand that loud voices of contention are not always necessary; to the extent that they voice discontent, one has to learn to listen between the lines of their discourse and understand their unique forms of agency.

Even so, the Dhofari women show signs of being willing and able to take responsibility for helping young people and making clear choices where they do exert their own agency. Furthermore, although the student-centered curriculum is being imposed on them by the Oman Ministry of Education, their styles for noticing and helping students indicate that they are likely to become part of the impetus for encouraging even greater attention to social and emotional sensitivity within their classrooms by allowing their students to be heard more and more.

As more Arab women are being educated, their agency will likely play a vital role in the social and political reforms that are spawning across the Arab countries. Even the little city of Salalah in southern Oman did not avoid a few citizen protests demanding more responsive government policy during the early months of 2011. Within the socially sanctioned career choices that young women enter, the agency that they exert may unobtrusively yet noticeably create further breaks from the past. These Dhofari women were not arguing in revolutionary voices for new roles in their society, yet they appeared to step up with resolution toward opportunities when offered them. Indeed, the young women of Salalah showed willingness combined with boldness and acceptance for taking actions that would not draw attention to themselves but that could lead to gradual change within the social systems of both families and schools.

\section{References}

Abu-Saad, I., Abu-Saad, K., Lewando-Hundt, G., Forman, M., Belmaker, I., Berendes, H., et al., 1998. Bedouin Arab mothers' aspirations for their children's education in the context of radical social change. International Journal of Educational Development 18 (4), 347-359.

Chatty, D., 1996. Harbingers of Change: Women and the Quest for Education. Mobile Pastoralists: Development Planning and Social Change in Oman. Columbia University Press, New York, pp. 143-163 (Chapter 7).

Chatty, D., 2000. Women working in Oman: individual choice and cultural constraints. International Journal of Middle East Studies 32 (2), 241-254.

Clarke, M., Otaky, D., 2006. Reflection "on" and "in" teacher education in the United Arab Emirates. International Journal of Educational Development 26 (1), 111122, doi:10.1016/j.ijedudev.2005.07.018

Emirbayer, M., Mische, A., 1998. What is agency? American Journal of Sociology 103 (4), 962-1023, doi:10.1086/231294.

Grigorenko, E.L., 2007. Hitting, missing, and in between: a typology of the impact of western education on the non-western world. Comparative Education (786636097), 165-186, doi:10.1080/03050060601162719.

Headland, T., Pike, K., Harris, M., 1990. Emics and Etics: The Insider/Outside Debate. Sage Publications, London.

Mazawi, A.E., 2002. Educational expansion and the mediation of discontent: the cultural politics of schooling in the Arab states. Discourse: Studies in the Cultural Politics of Education 23 (772815468), 59-74, doi:10.1080/ 0159630022012304.

Paltridge, B., 2006. Discourse Analysis: An Introduction. Continuum, London.

Peterson, J.E., 2004. Oman: three and a half decades of change and development. Middle East Policy XI (2), 125-137.

Rassekh, S., 2004. Education as a Motor for Development: Recent Education Reforms in Oman with Particular Reference to the Status of Women and Girls. UNESCO, International Bureau of Education, Geneva, pp. 1-47.

Richardson, P., 2004. Possible influences of Arabic-Islamic culture on the reflective practices proposed for an education degree at the Higher Colleges of Technology in the United Arab Emirates. International Journal of Educational Development 24 (4), 429-436, doi:10.1016/j.ijedudev.2004.02.003.

Schön, D., 1983. The Reflective Practitioner: How Professionals Think in Action. Basic Books, New York.

Stodden, R., Hamada, C., Simonelli, S., Nagasako, J., 2003. Social Emotional Learning Brief. , Retrieved from www.sig.hawaii.edu/products/briefs/sel_ brief.pdf. 
UNDP, 2006. The Arab Human Development Report 2005: Towards the Rise of Women in the Arab World. Human Development, New York.

UNESCO, 2000. EFA 2000 Assessment - Country Reports: Oman. , Retrieved from http://www.unesco.org/education/wef/countryreports/oman/contents. html.

UNESCO, 2002. Arab States Regional Report. Statistics. Montreal, Canada.

UNESCO, 2008. Regional Overview: Arab States EFA Progress and Challenges. Changes. , Retrieved fromwww.efareport.unesco.org.

van Dijk, T.A., 2008. Discourse and Context: A Sociocognitive Approach. Cambridge University Press, Cambridge.
Weiner Levy, N., 2009. “... but it has its price”: cycles of alienation and exclusion among pioneering Druze women. International Journal of Educational Development 29 (1), 46-55, doi:10.1016/j.ijedudev.2008.04.005.

Wikan, U., 1982. Behind the Veil in Arabia: Women in Oman. University of Chicago Press, Chicago.

Williamson, J., 2006. Dhofar and Its Struggle with the English Language. St Clements University (supervised by London Teaching Training Center).

Wyatt, M., Atkins, J., 2009. Introduction. In: Wyatt, M., Atkins, J. (Eds.), Research Perspectives on Education in Oman. Ministry of Education, Sultanate of Oman, pp. viii-Xv. 